\title{
First Report on Identification of Fusarium graminearum Species Complex Members from Turkey and Iran
}

\author{
Berna Tunalı1,a, Emre Yörüik ${ }^{2, b, *}$, Özlem Sefer, ${ }^{2, \mathrm{c}}$, Bayram Kansu ${ }^{3, \mathrm{~d}}$, Bahram Sharifnabi ${ }^{4, e}$ \\ ${ }^{1}$ Department of Plant Pathology, Faculty of Agriculture, Samsun Ondokuz Mayis University, 55270 Atakum/Samsun, Turkey \\ ${ }^{2}$ Department of Molecular Biology and Genetics, Faculty of Arts and Sciences, Istanbul Yeni Yuzyil University, 34010 Istanbul, Turkey \\ ${ }^{3}$ Animal and Plant Production Department, Vocational School, Samsun Ondokuz, Mayis University, S55270 Atakum/Samsun, Turkey \\ ${ }^{4}$ Department of Plant Protection, College of Agriculture, Isfahan University of Technology, Isfahan, Iran \\ *Corresponding author
}

\begin{tabular}{|c|c|}
\hline A R T I C L E I N F O & A B S T R A C T \\
\hline $\begin{array}{l}\text { Keywords: } \\
\text { DNA Sequencing } \\
\text { Fusarium graminearum } \\
\text { Fusarium Head Blight } \\
\text { Multilocus Genotyping } \\
\text { Species Complex }\end{array}$ & $\begin{array}{l}\text { Fusarium graminearum species complex is the major Fusarium head blight disease pathogen in } \\
\text { worldwide. Fusarium head blight disease lead to damages on small grain cereals. The identification } \\
\text { of the F. graminearum species complex is important for improving disease control and management. } \\
\text { Traditional identification methods such as macroscopy and microscopy analysis need to be } \\
\text { supported by biochemical and genetics assays. Thus, DNA sequencing-based methods is one of the } \\
\text { most preferred, reliable, low priced in the identification methods. In the study, } 54 \text {. graminearum } \\
\text { isolates obtained from diseased wheat, barley and corn fields in Turkey and Iran were identified by } \\
\text { morphological characteristics and then characterized by species-specific SCAR marker. } \beta \text {-tubulin, } \\
\text { Tef1- } \alpha, 28 \text { s rDNA and Histone H3 genes amplified, purified and then sequenced. The merged } \\
\text { multiloci length was obtained as last of all } 2215 \text { bp. These sequencing results was used to multiloci } \\
\text { genotyping assays. Last of all, } 20 \text { isolates were determined as F. graminearum sensu stricto by } \\
\text { multiloci genotyping analysis. Remaining isolates were identified as F. asiaticum or Fusarium sp. } \\
\text { The findings are important in terms of revealing the first-time identification in Turkish and Iranian } \\
\text { isolates as F. graminearum species complex members by amplification four ( } \beta \text {-tubulin, Tef1- } \alpha, 28 \mathrm{~s} \\
\text { rDNA and Histone H3) highly conserved DNA regions. }\end{array}$ \\
\hline
\end{tabular}

\section{Introduction}

Fusarium head blight (FHB) is a major destructive disease of some small grain cereals and is closely related to primary food safety concern. Many Fusarium species can lead to FHB and epidemics of these species and their associated mycotoxins have been occurred in many different regions (Parry et al., 1995; Logrieco et al., 2002; Goswami and Kistler, 2004). Fusarium graminearum is known to be the important causal agent of FHB from many regions worldwide (Pasquali and Migheli, 2014). Several cereals, such as wheat, barley and maize, are infected by $F$. graminearum and substantial yield losses reaching up to billions of dollars, reduction in crop quality and health problems with severe levels are observed. F. graminearum, as called $F$. graminearum species complex (FGSC), has been reported to show high level of genetic diversity in the worldwide and this variable population genetics potential led to a continuous increase in genetic characterization studies. (Miedaner et al., 2008, 2013; Matny, 2015; Taheri, 2018).
Since identification of phytopathogens at species level precisely is important in disease management, researchers have been focused on genetic characterization of $F$. graminearum more than 30 years. The first striking data for this species was about to distinguish $F$. graminearum and $F$. pseudograminearum as two different species (Aoki and O'Donnell, 1999). After that, second important advance in $F$. graminearum characterization was the lineage differentiation up to seven members by nuclear gene sequencing and SCAR markers (O'Donnell et al., 2000; Carter et al., 2002). Recently, the number of phylogenetically distinct species for $F$. graminearum species complex is 15 . Nuclear gene sequence variation has been clearly related to chemotype and geographic distribution up to now and the cosmopolitan member has been reported as $F$. graminearum sensu stricto (O'Donnell et al., 2000; Wang et al., 2008; Yli-Mattila et al., 2009; Przemieniecki et al., 2014). 
The close association between $F$. graminearum and FHB have been reported many European and Asian countries including Turkey in last two decades (Miedaner et al., 2008; Pasquali and Migheli, 2014; Matny, 2015; Taheri, 2018). The identification of FGSC is a critical step to control of mycotoxin contamination and improving disease management. Conventional methods based on morphological characters, are commonly used in for discrimination of species in Fusaria. However, these methods could require labour and insufficient alone. Thus, DNA sequencing-based methods have been preferred for credible, fast, reliable and cost-effective strategies for species identification currently. In this study, for the first time, F. graminearum isolates causing FHB and crown rot diseases from Turkey and Iran have been subjected to FGSC member identification by multiple sequencing assays with amplification of $\beta$-tubulin, Histone H3, TEF1$\alpha$ (Translation elongation factor) and ITS-28S rDNA regions.

\section{Materials and Methods}

\section{Fungal Materials}

Isolates were obtained from wheat, barley and maize fields from plant crown and ear parts near plant maturity between the years 2006-2017. Surface sterilization, in vitro growth and microscopic assays were carried out as described by Tunali et al. (2006). Single spore isolations were carried out by using a common protocol described by Burgess et al. (1994). Totally, 54 single spore isolates of $F$. graminearum were used in further analysis. Characteristics of $F$. graminearum isolates are given in Table 1 .

\section{Genomic DNA Extraction}

Genomic DNA (gDNA) was isolated from 7-day-old cultures grown on Czapek-Dox Agar (CDA) at $26 \pm 2^{\circ} \mathrm{C}$ using the sodium dodecyl sulphate-based protocol. 50$100 \mathrm{mg}$ fresh mycelium was collected from petri dishes and washed with $96 \%$ ethanol for 3 mins. Dried mycelium was homogenized in liquid nitrogen with mortar and pestle. The homogenate was transferred to a sterile microtube and the binding $500 \mu \mathrm{L}$ lysis buffer $(100 \mathrm{mM}$ Tris-Cl, $100 \mathrm{mM}$ EDTA, $1 \mathrm{M} \mathrm{NaCl}, 1 \% \mathrm{SDS}$ and $1 / 500 \beta$-mercaptaetanol) was added to tubes, and homogenization was carried out by throughout vertexing. $10 \mu \mathrm{L}$ of RNase A $(10 \mathrm{mg} / \mathrm{mL})$ was added to tubes and incubated at $65^{\circ} \mathrm{C}$ for 15 mins. $700 \mu \mathrm{L}$ chloroform:isoamylalchol $(24: 1)$ was added to tubes and gently mixed. After centrifugation at $13.000 \mathrm{rpm}$ for $1 \mathrm{~min}$, supernatant was transferred to new tube and 1:1 volume of chloroform:isoamylalchol (24:1) was added. After centrifugation 1:10 volume $\mathrm{NaOAc}$ and 2 volumes of cold $96 \%$ ethanol was added to tubes. Samples were incubated at $-80^{\circ}$. Samples were then centrifuged at $13.000 \mathrm{rpm}$ for 5 min. Tubes were washed $70 \%$ ethanol with two times and after centrifugation at $13.000 \mathrm{rpm}$ for $2 \mathrm{~min}$, ethanol was removed and gDNA was eluted in $50 \mu \mathrm{L} \mathrm{ddH}_{2} \mathrm{O}$. The purity and the quantity of extracted gDNA molecules were checked with spectrophotometer (Thermo, USA) and 1\% agarose gel electrophoresis. gDNA was photographed underusing a gel documentation system (Maestrogen, Taiwan) by staining with $0.2-0.5 \mu \mathrm{g} / \mathrm{mL}$ ethidium bromide under UV light. Electrophoresis was carried out under 70V for $45 \mathrm{~min}$. Intact gDNA molecules were diluted to 10 $\mathrm{ng} / \mu \mathrm{L}$ dilution series in order to use them in further assays.

Table $1 F$. graminearum isolates used in this study. ' $*$ ', means positive EcoRV digestion.

\begin{tabular}{|c|c|c|c|c|c|c|c|}
\hline Code & Host & Location & Year & Code & Host & Location & Year \\
\hline F5 & Wheat & Sakarya & 2006 & FgM6 & Wheat & Mazandaran & 2007 \\
\hline $\mathrm{F} 6 *$ & Wheat & Sakarya & 2006 & FgM7 & Wheat & Mazandaran & 2007 \\
\hline $\mathrm{F} 7 *$ & Wheat & Sakarya & 2006 & FgM9 & Wheat & Mazandaran & 2007 \\
\hline F8 & Wheat & Sakarya & 2006 & FgM10 & Wheat & Mazandaran & 2007 \\
\hline $\mathrm{F} 9 *$ & Wheat & Balikesir & 2006 & $\mathrm{Fg} 4$ & Wheat & Mazandaran & 2007 \\
\hline $1 \mathrm{~F}$ & Wheat & Bolu & 2010 & FgM5 & Wheat & Mazandaran & 2007 \\
\hline $2 \mathrm{~F}$ & Wheat & Cankiri & 2009 & $\mathrm{Fg} 5$ & Wheat & Sari & 2007 \\
\hline $3 \mathrm{~F}$ & Maize & Samsun & 2010 & $\mathrm{Fg} 18 *$ & Wheat & Moghon & 2007 \\
\hline $4 \mathrm{~F}$ & Barley & Bolu & 2010 & Fg49 & Wheat & Moghon & 2007 \\
\hline $5 \mathrm{~F} *$ & Maize & Samsun & 2010 & Fg56 & Wheat & Gorgan & 2007 \\
\hline $6 \mathrm{~F}$ & Maize & Samsun & 2010 & $\mathrm{Fg} 165 *$ & Wheat & Kordkooy & 2007 \\
\hline $7 \mathrm{~F}$ & Maize & Samsun & 2010 & $\mathrm{Fg} 170$ & Wheat & Gorgan & 2007 \\
\hline $14 \mathrm{~F}^{*}$ & Wheat & Kastamonu & 2009 & $\operatorname{Fg} 174 *$ & Wheat & Gorgan & 2007 \\
\hline $15 \mathrm{~F} *$ & Wheat & Sakarya & 2010 & Fgsh1 & Wheat & Mazandaran & 2007 \\
\hline 14-4TR & Wheat & Tokat & 2014 & Fgsh $4 *$ & Wheat & Mazandaran & 2007 \\
\hline $14-5 \mathrm{TR}^{*}$ & Wheat & Amasya & 2014 & Fgsh5 & Wheat & Mazandaran & 2007 \\
\hline $14-6 \mathrm{TR} *$ & Wheat & Tokat & 2014 & Fgsh7 & Wheat & Mazandaran & 2007 \\
\hline $14-7 \mathrm{TR} *$ & Wheat & Amasya & 2014 & Fgsh10 & Wheat & Mazandaran & 2007 \\
\hline $10-2 \mathrm{TR} *$ & Maize & Samsun & 2010 & FgSh13 & Wheat & unknown & 2007 \\
\hline 17-9TR & Wheat & Samsun & 2017 & Fgsh15 & Wheat & Unknown & 2007 \\
\hline $17-11 \mathrm{TR} *$ & Wheat & Samsun & 2017 & FgT2 & Wheat & Mazandaran & 2007 \\
\hline $17-12 \mathrm{TR} *$ & Wheat & Samsun & 2017 & FgT3 $*$ & Wheat & Mazandaran & 2007 \\
\hline 17-13TR * & Wheat & Samsun & 2017 & FgT7 & Wheat & Mazandaran & 2007 \\
\hline $17-14 \mathrm{TR} *$ & Wheat & Samsun & 2017 & FgT9 * & Wheat & Mazandaran & 2007 \\
\hline $17-15 \mathrm{TR} *$ & Wheat & Samsun & 2017 & FgT10 & Wheat & Mazandaran & 2007 \\
\hline $17-16 \mathrm{TR} *$ & Wheat & Samsun & 2017 & $\operatorname{FgT1} 11 *$ & Wheat & Mazandaran & 2007 \\
\hline FgM1 $*$ & Wheat & Neka & 2007 & FgT16 & Wheat & Mazandaran & 2007 \\
\hline
\end{tabular}


Species Specific Identification by Polymerase Chain Reaction (PCR) Assays

Species-specific identification was carried out by two different species-specific SCAR primers.

UBC85F/UBC85R primer set developed by Schilling et al. (1996) was used in order to amplify monomorphic bands of 332 bp DNA. PCRs were carried out in a volume of $25 \mu \mathrm{L}$ containing $50 \mathrm{ng}$ genomic DNA, 1X PCR master mix (Takara, Japan) and 5 pmol of each primer. PCR conditions were performed at $98^{\circ} \mathrm{C}$ for $2 \mathrm{~min}$ for predenaturation, 35 cycles at $94^{\circ} \mathrm{C}$ for $30 \mathrm{~s}, 61^{\circ} \mathrm{C}$ for $30 \mathrm{~s}, 72^{\circ} \mathrm{C}$ for $30 \mathrm{~s}$ and at $72^{\circ} \mathrm{C}$ for $2 \mathrm{~min}$ for final extension. The amplicons were electrophoresed in $1.5 \%$ agarose gels and stained with EtBr. The gel images were obtained as described before.

\section{Multiloci Genotyping by PCR and Bioinformatics Assays}

To discriminate the members of $F$. graminearum species complex specific and highly conserved DNA regions were targeted in multiple alignment assays. For this purpose, $\beta$-tubulin, Histone H3, TEF1- $\alpha$ (Translation elongation factor) and ITS-28S rDNA regions were amplified. PCR primers (Starkey et al. 2007) are given in Table 2. $50 \mu \mathrm{L}$ volume of PCRs mixtures included $1 \mathrm{X}$ PCR mix (Takara, Japan), 10 pmol of each primer, and 50ng of gDNA. PCR cycling conditions were as follows: predenaturation at $98^{\circ} \mathrm{C}$ for $3 \mathrm{~min} ; 35$ cycles of $98^{\circ} \mathrm{C}$ for $30 \mathrm{~s}$, $50-55^{\circ} \mathrm{C}$ for $30 \mathrm{~s}, 72^{\circ} \mathrm{C}$ for $1-2 \mathrm{~min}$; final extension at $72^{\circ} \mathrm{C}$ for $3 \mathrm{~min}$. PCR bands were analyzed as described before on $1.5 \%$ agarose gels. After checking the correct bands on agarose gels, bands were purified by using a commercial PCR product clean up kit (BioBasic, Canada). Agarose gel pieces of $100 \mathrm{mg}$ were cut form the gels and the protocol provided by the manufacturer was followed in amplicon purification.

Sanger dideoxy termination method-based sequencing process was carried out using "DYEnamic ET Terminator Cycle Sequencing" kit (Amersham, USA) on ABI PRISM 310 device. The nucleotide sequence related signal pics were displayed on chromatograms using the "Chromas Lite Edition" software. The sequences translated to FASTA format were subjected to BLASTN analysis. After BLASTN check, the nucleotide sequences generated via forward and reverse primers were aligned and assembled into a single sequence via DNA Dragon software. These sequences were subjected to multiple alignment and neighbor joining (NJ) topology assays by Mega 6.0 software (Tamura et al., 2013). Accession numbers reported from different investigations of (O'Donnell et al., 2000; 2008; Yli-Mattila et al., 2009; Starkey et al., 2007; Tóth et al 2008; Desjardins and Proctor 2011) for each gene of every species complex members were used as positive control in alignment assays. Each gene was both aligned single and multiple as a single FASTA file by using multiple alignment assays. Histone $\mathrm{H} 3$ sequences obtained from Turkish and Iranian isolates were also subjected to PCR-RFLP based sequencing strategy developed by O'Donnell et al. (2004) was also used in order to confirm the presence of $F$. graminearum sensu stricto or $F$. asiaticum members in isolates used in this study.

Table 2 Primers used in this study.

\begin{tabular}{l|lllr}
\multicolumn{1}{c}{ Primer set } & \multicolumn{1}{c}{ Forward sequence (5'-3') } & Reverse sequence (5'-3') & Gene & Band size (bp) \\
\hline Ef1/2 & atgggtaaggargacaagac & ggargtaccagtsatcatgtt & TEF1- $\alpha$ & 700 \\
btubcodonF/R & gtcattacaccgagggtgct & gaggcagccatcatgttctt & $\beta$-tubulin & 603 \\
HistonH3.2F & aggtccactggtggcaag & atgtccttggactggatggt & Histone H3 & 482 \\
ITS5/NL4 & ggaagtaaaagtcgtaacaagg & ggtccgtgttcaagacgg & ITS-28S rDNA & 1200 \\
\hline
\end{tabular}

\section{Results and Discussion}

$F$. graminearum isolates obtained from diseased wheat, barley and maize samples of Turkey and Iran were confirmed by morphological characteristics as reported by Tunali et al. (2006). After morphologic characterization by microscopy, isolates were confirmed at species level by SCAR markers. Each isolate yielded 332 bp amplicon by UBC85F/R primer set (data not shown). These results showed that each isolate, used in this study, could be accepted as $F$. graminearum species complex.

After species-specific identification of $F$. graminearum isolates by common methods, multiloci genotyping was used to further identify isolates as members for FGSC. Totally four genes were amplified from 54 isolates. Predicted amplicon sizes, given in Table 2, were obtained by PCR assays (Figure 1). Each amplicon was cleaned up and then sequenced. After obtaining two directional sequences for each isolate; the data was assembled. Before final version of trimmed sequences, each nucleotide sequence was independently subjected to BLASTN analysis. BLASTN analysis resulted in highly conserved
DNA regions with reference $F$. graminearum nucleotide sequences on GenBank (bit scores $>50$ and $E$ value $<0.05$ ). After BLASTN assays, the sequences were trimmed and the trimmed final nucleotide sequence length for $\beta$-tubulin, Histone H3, TEF1- $\alpha$ and ITS-28S rDNA regions were extracted as approximately 285, 375, 605 and $950 \mathrm{bp}$ length, respectively. The merged total sequence length was approximately $2215 \mathrm{bp}$. The deletions/insertions and substitutions were detected by multiple alignment for some isolates leading to genetic polymorphisms (Figure 2). The isolates containing same deletions/insertion were positioned in the same sub-division with reference sequence. In maximum likelihood topology analysis, two distinct divisions (Div-1 and Div-2) were obtained via 1000 hierarchical replicates (Figure 3). Div-1 included 5 isolates while Div-2 contained remaining 49 isolates from Turkey and Iran. Two reference strains, $F$. graminearum sensu stricto and $F$. asiaticum, were clustered in Div-2. 14 Turkish (17-14TR, 17-13TR, 17-12TR, 17-11TR, 1715TR, F6, 15F, 14F, 14-7TR, 14-6 TR, 14-5 TR, 5F, 10- 
2TR and F7) and 6 Iranian (Fg18, Fg165, Fg174, FgT3, FgT11 and Fgsh4) isolates were closely related to reference F. graminearum sensu stricto in Subdiv-1 of Div-2. Twenty-four Turkish and Iranian isolates were coclustered with $F$. asiaticum reference strain in sub-div-2 of Div-2. EcoRV digestion of Histon $\mathrm{H} 3$ nucleotide sequence dependent assay resulted so similar results from multiloci genotyping assay. EcoRV digestion positive isolates were given in Table 1 with asterisk. F graminearum sensu stricto positive isolates were co-clustered in sub-div-1 of Div-2. These results clearly showed that only 20 isolates used in this study (17-14TR, 17-13TR, 17-12TR, 17-11TR, 1715TR, F6, 15F, 14F, 14-7TR, 14-6TR, 14-5 TR, 10-2TR, 5F, F7, Fg18, Fg165, Fg174, FgT3, FgT11 and Fgsh4) belonged to $F$. graminearum sensu stricto while 25 isolates (4F, F8, F5, 2F, 6F,7F, Fg170, FgSh5, FgM9, Fg5, FgSh15, Fg56, Fg49, FgT7, FgT10, 1F, FgSh7, FgT2, FgM6, FgM10, FgT16, FgM5, FgSh13, FgM7 and FgSh10) were closely related to $F$. asiaticum. Remaining 9 isolates (17-9TR, FgM1, FgT9, Fg4, F9, 17-16TR, 3F, FgSh1 and 14-4TR) clustered in Div-1 and Div-2 could be accepted as Fusarium sp. as reported by Przemieniecki et al. (2014).

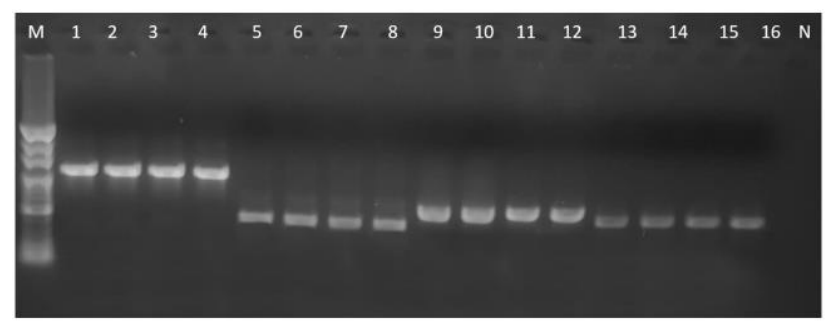

Figure $1 \beta$-tubulin, Histone H3, TEF1- $\alpha, 28 \mathrm{~S}$ rDNA genes amplified from $F$.graminearum isolates.

$\mathrm{N}$ : negative control, M: 100bp size marker (Genemarkbio, Taiwan), 1-4: 28S rDNA, 5-8: Histone H3, 9-12: TEF1- $\alpha$, 13-16: $\beta$-tubulin PCR product.

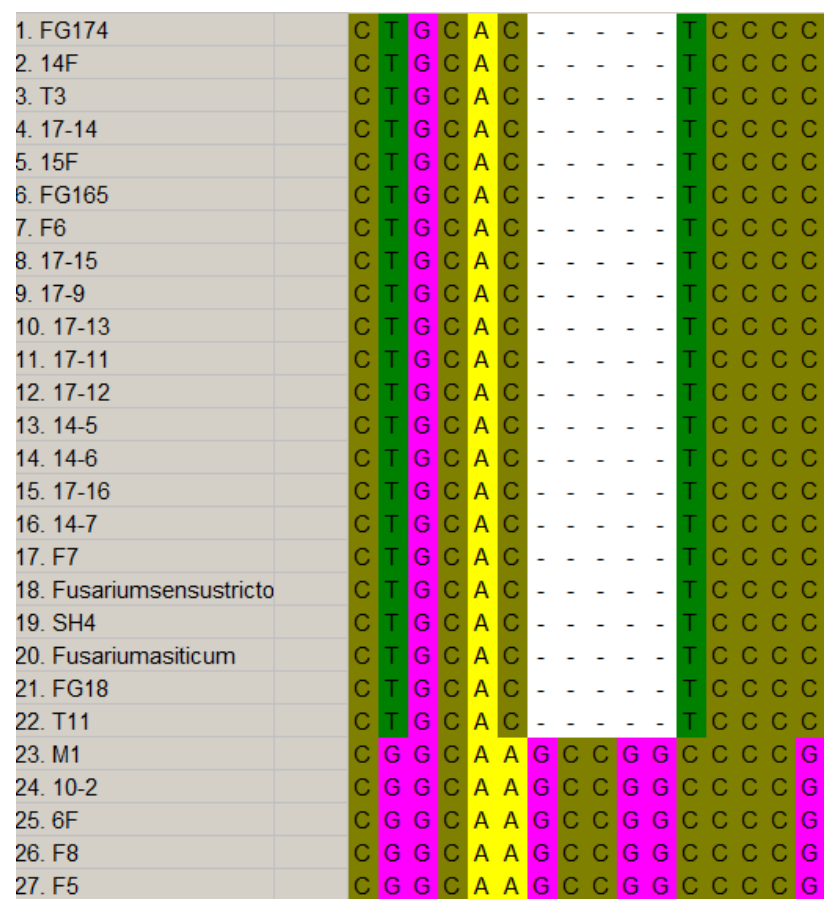

Figure 2 Deletion/insertion and substitutions on multiple alignment profile obtained by Mega 6.0 software
In phylogenetics analysis obtained from multiple alignment of multiloci sequencing, isolates belonged to the collection years 2006, 2014 and 2017 showed strong correlation in clustering analysis. Isolates from these years were co-clustered in the same sub divisions together in phylogram. This result was compatible with previous reports including Fusarium isolates from different locations by different molecular marker analysis including RAPD, PCR-RFLP and allele-specific PCR assays (Carter et al., 2000; Saharan et al., 2007; Çepni et al., 2013; Yörük et al., 2018). Similarly, isolates from the same or near agroecological location (s) were clustered so closely in phylogram. Even if the precise correlation between geographic origin and clustering of Fusarium isolates can't be stated whenever, locations can be accepted as a major characteristic behind the variation of Fusarium isolates (Carter et al., 2000, 2002; Mishra et al., 2004; Miedaner et al., 2001, 2008; Yörük and Albayrak, 2013). Most of the isolates used in this study were obtained from wheat as the host. As seen in Figure 3, isolates obtained from maize were phylogenetically closely located at dendrogram. It seems that, characteristics for phylogenetical differentiation of FGSC isolates used in this study should be considered together. In other words, location, collection year and belonging to different species complex member could play collectively. By this way, location is predominating factor to differentiate among the isolates. However, collection year was another strong factor to identify FGSC isolates comprehensively. Chemotype and diseases could be variable within FGSC members. The head blight disease is the most frequently observed disease for both $F$. asiaticum and $F$. graminearum sensu stricto While these two species were detected in Asia, but $F$. graminearum sensu stricto has been reported as global pathogen worldwide. Both species could produce 3acetyldeoxynivalenol, 15-acetyldeoxynivalenol and nivalenol while some other members can't produce these three myxotoxins (Przemieniecki et al., 2014).

Fifteen members for $F$. graminearum species complex have been present, recently (Przemieniecki et al., 2014). In this study, twenty isolates were clearly identified as $F$. graminearum sensu stricto by EcoRV digestion and multiloci genotyping analysis. Remaining isolates were identified as $F$. asiaticum or Fusarium sp. This study is important in terms of presenting the detailed differentiation of Turkish and Iranian F. graminearum isolates as FGSC members. FGSC identification studies included confusing, hesitant and inexact information up to now (Yörük and YliMattila, 2015). Thus, to support the data obtained from SCAR markers, multiloci genotyping and genealogical concordance analysis by next generation sequencing assays (including genome wide haplotyping) would be useful to obtain more detailed knowledge in further studies. This study presents knowledge about the presence of FGSC members in Turkey and Iran. The studies including the increased number of Turkish and Iranian $F$. graminearum isolates would provide detailed and comprehensive data for FGSC characterization in Turkey and Iran.

\section{Acknowledgements}

This work was supported by the Board Regents of Istanbul Yeni Yuzyil University under Grant number 6047. 


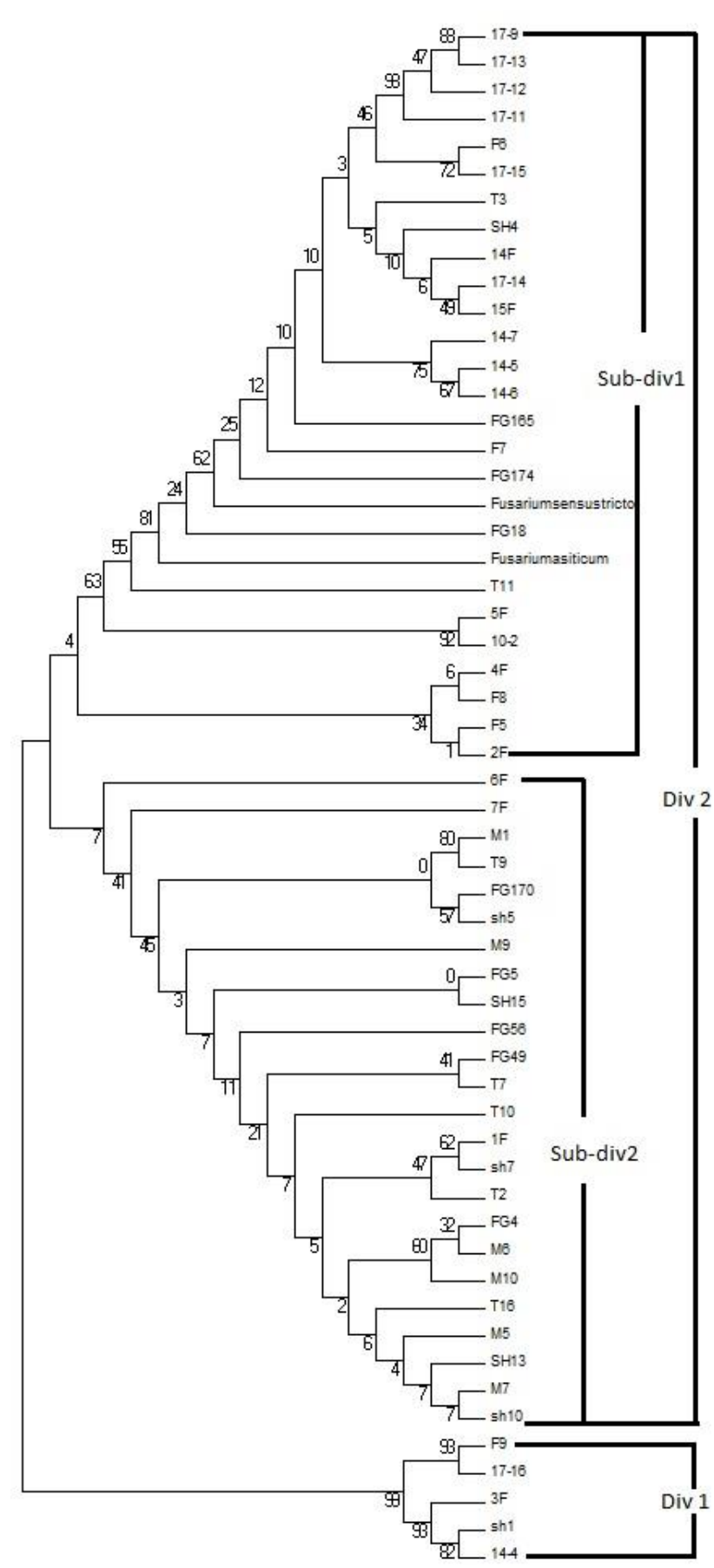

Figure 3 Filogenetic tree of $F$. graminearum isolates was obtained by maximum likelihood analysis

\section{References}

Aoki T, O’Donnell K. 1999 Morphological and molecular characterization of Fusarium pseudograminearum sp. nov., formerly recognized as the Group 1 population of $F$. graminearum. Mycologia, 91 (4): 597-609.

Burgess T, Dell B, Malajczuk N. 1994. Variation in mycorrhizal development and growth stimulation by 20 Pisolithus isolates inoculated on to Eucalyptus grandis W. Hill ex Maiden. New Phytol., 127(4): 731-739.

Carter J., Rezanoor HN, Desjardins AE, Nicholso, P. 2000. Variation in Fusarium graminearum isolates from Nepal associated with their host of origin. Plant Pathol., 49(4): 452460.
Carter JP, Rezanoor HN, Holden D, Desjardins AE, Plattner RD, Nicholson P. 2002. Variation in pathogenicity associated with the genetic diversity of Fusarium graminearum. Eur J Plant Pathol., 108(6): 573-583.

Çepni E, Tunalı B, Gürel F. 2012. Genetic diversity and mating types of Fusarium culmorum and Fusarium graminearum originating from different agro-ecological regions in Turkey. J Basic Microbiol., 52: 1-9. https://doi.org/10.1002 /jobm.201200066

Desjardins AE, \& Proctor RH. 2011. Genetic diversity and trichothecene chemotypes of the Fusarium graminearum clade isolated from maize in Nepal and identification of a putative new lineage. Fungal Biol., 115(1): 38-48. https://doi.org/10.1016/j.funbio.2010.10.002

Goswami RS, Kistler HC. 2004. Heading for disaster: Fusarium graminearum on cereal crops. Mol Plant Pathol., 5(6): 515525. https://doi.org/10.1111/J.1364-3703.2004.00252.X

Logrieco A, Mule G, Moretti A, Bottalico A. 2002. Toxigenic Fusarium species and mycotoxins associated with maize ear rot in Europe. Eur J Plant Pathol., 108: 597-609. https://doi.org/10.1023/A:1020679029993

Matny ON. 2015. Fusarium head blight and crown rot on wheat \& barley: losses and health risks. Adv Plants Agric Res., 2(39): 10-15406.

Miedaner T, Schilling AG, Geiger HH. 2001. Molecular genetic diversity and variation for aggressiveness in populations of Fusarium graminearum and Fusarium culmorum sampled from wheat fields in different countries. J Phytopathol., 149(11-12): 641-648.

Miedaner T, Cumagun CJR, Chakraborty S. 2008. Population genetics of three important head blight pathogens Fusarium graminearum, F. pseudograminearum and F. culmorum. J Phytopathol., 156(3): 129-139.

Miedaner T, Caixeta F, Talas F. 2013. Head-blighting populations of Fusarium culmorum from Germany, Russia, and Syria analyzed by microsatellite markers show a recombining structure. Eur J Plant Pathol, 137(4): 743-752. https://doi.org/10.1007/s10658-013-0284-6

Mishra PK, Tewari JP, Clear RM, Turkington TK. 2004. Molecular genetic variation and geographical structuring in Fusarium graminearum. Ann Appl Biol., 145(3): 299-307.

O'Donnell K, Kistler HC, Tacke BK, Casper HH. 2000. Gene genealogies reveal global phylogeographic structure and reproductive isolation among lineages of Fusarium graminearum, the fungus causing wheat scab. Proc Natl Acad Sci., 97(14): 7905-7910.

O’Donnell K, Ward TJ, Geiser DM, Kistler HC, Aoki T. 2004. Genealogical concordance between the mating type locus and seven other nuclear genes supports formal recognition of nine phylogenetically distinct species within the Fusarium graminearum clade. Fungal Genet Biol., 41(6): 600-623. https://doi.org/10.1016/j.fgb.2004.03.003

O’Donnell K, Ward TJ, Aberra D, Kistler HC, Aoki T, Orwig N, ..., Klemsdal SS. 2008. Multilocus genotyping and molecular phylogenetics resolve a novel head blight pathogen within the Fusarium graminearum species complex from Ethiopia. Fungal Genet Biol., 45(11): 1514-1522. https://doi.org/10.1016/j.fgb.2008.09.002

Parry DW, Jenkinson P, McLeod L. 1995. Fusarium ear blight (scab) in small grain cereals-a review. Plant Pathol., 44(2): 207-238.

Pasquali M, Migheli Q. 2014. Genetic approaches to chemotype determination in type B-trichothecene producing Fusaria. International J Food Microbiol., 189: 164-182. https://doi.org/10.1016/j.ijfoodmicro.2014.08.011

Przemieniecki SW, Kurowskİ TP, Korzekwa K. 2014. Chemotypes and geographic distribution of the Fusarium graminearum species complex. Environ Biotechnol, 10(2): 45-59. https://doi.org/10.14799/ebms241 
Saharan MS, Naef A, Kumar J, Tiwari R. 2007. Characterization of variability among isolates of Fusarium graminearum associated with head scab of wheat using DNA markers. Curr Sci., 230-235. https://www.jstor.org/stable/24096694

Schilling AG, Moller EM, Geiger HH. 1996. Polymerase chain reaction-based assays for species-specific detection of Fusarium culmorum, $F$. graminearum, and $F$. avenaceum. Phytopathol., 86(5): 515-522. https://doi.org/10.1094/Phyto86-515

Starkey DE, Ward TJ, Aoki T, Gale LR, Kistler HC, Geiser DM, O'Donnell K. 2007. Global molecular surveillance reveals novel Fusarium head blight species and trichothecene toxin diversity. Fungal Genet Biol., 44(11): 1191-1204.

Taheri P. 2018. Cereal diseases caused by Fusarium graminearum: from biology of the pathogen to oxidative burst-related host defense responses. Eur J Plant Pathol., 120. https://doi.org/10.1007/s10658-018-1471-2

Tamura K, Stecher G, Peterson D, Filipski A, Kumar S. 2013. MEGA6: molecular evolutionary genetics analysis version 6.0. Mol Bio Evol., 30(12): 2725-2729. https://doi.org/10.1093/molbev/mst197

Tóth B, Kaszonyi G, Bartok T, Varga J. Mesterhazy A. 2008. Common resistance of wheat to members of the Fusarium graminearum species complex and $F$. culmorum. Plant Breed., 127(1): 1-8. https://doi.org/10.1111/j.14390523.2008.01412.x

Tunali B, Ozseven I, Buyuk O, Erdurmus D, Demirc, A. 2006. Fusarium head blight and deoxynivalenol accumulation of wheat in Marmara region and reactions of wheat cultivars and lines to $F$. graminearum and $F$. culmorum. Plant Pathol J., 5(2):150-156
Wang JH, Li HP, Qu B, Zhang JB, Huang T, Chen FF, Liao YC. 2008. Development of a generic PCR detection of 3acetyldeoxynivalenol-, $\quad 15$-acetyldeoxynivalenol-and nivalenol-chemotypes of Fusarium graminearum clade. Int $\mathbf{J}$ Mol Sci., 9(12): 2495-2504. https://doi.org/10.3390 /ijms9122495

Yli-Mattila T, Gagkaeva T, Ward TJ, Aoki T, Kistler HC, O'Donnell K. 2009. A novel Asian clade within the Fusarium graminearum species complex includes a newly discovered cereal head blight pathogen from the Russian Far East. Mycologia, 101(6): 841-852. https://doi.org/10.3852/08-217

Yörük E, Albayrak G. 2013. Genetic characterization of Fusarium graminearum and $F$. culmorum isolates from Turkey by using random-amplified polymorphic DNA. Genet Mol Res, 12(2): 1360-72. https://doi.org/10.4238 /2013.April.25.7

Yörük E, Yli-Mattila T. 2015. Sequence Characterized Amplified Region Marker Usage in Identification of Phytopathogenic Fusarium species. Ulusal Moleküler Biyoloji ve Biyoteknoloji Kongresi, 21-24 Ağustos, Afyon, Türkiye, S 106.

Yörük E, Sefer Ö, Tunali B, Kansu B, Sharifnabi B, Yli-Mattila T. 2018. Thiophanate methyl susceptibility and alterations in tri5, Mgvl and StuA expression among Fusarium graminearum and $F$. culmorum isolates. J Plant Pathol., 100: 447-455. https://doi.org/10.1007/s42161-018-0094-y 